Bull. Mater. Sci., Vol. 4, Number 3, May 1982, pp. 247-259. (C) Printed in India.

\title{
Eutectic growth in space
}

\author{
A M SRIRAMAMURTHY and V S ARUNACHALAM \\ Defence Metallurgical Research Laboratory, Hyderabad 500258 , India
}

MS received 17 June 1980

\begin{abstract}
Defect-free eutectic components are favoured for certain applications in view of their improved performance and/or better stability. Eutectics produced even under best conditions possible on earth have some microstructural defects. Unavoidable density driven convectional currents in liquid are considered as a major cause for the production of these defects. Intensity of such convectional currents proportionally reduces with gravity. Therefore the defect density in the eutectics is expected to be very low when processed under microgravity conditions. The advantages and limitations of processing under microgravity conditions are examined. The potential of newly developed 'skin technology' for processing eutectic components in space is considered.
\end{abstract}

Keywords. Eutectic; in-situ composite; microgravity space; directional solidification; eonvectional currerts.

\section{Introduction}

In the recent past much interest is shown in directionally solidified eutectic alloys due to their unique properties-mechanical, physical and electronic. Stability and performance demanded by some applications require defect-free structures. Some of the defects cannot be eliminated on earth due to unavoidable convection. The microgravity conditions in Spacelab facilitate production of eutectics under these canditions and assessing them. The present paper examines the potentials of microgravity-processed eutectics.

\section{Background}

The eutectic reaction is one in which a liquid decomposes into two or more solid phases at a temperature characteristic to that alloy. A eutectic reaction is possible anly in multicomponent systems (i.e., binary, ternary allays, etc.). In a binary alloy the eutectic contains two solid phases, and in ternary alloy there are three solid phases. At the eutectic reaction point the compositions as also the temperature of all phases are fixcd. Thus it has no degrees of freedom. Applying Gibb's phase rule, onc derives the number of phases in a eutectic reaction as equal to the number of components at a constant pressure.

A simple binary phase diagram, thet of the $\mathrm{Ag}-\mathrm{Cu}$ system is shown in figure 1. In this alloy, a liquid containing $28.5 \% \mathrm{Cu}$ freezes into two solid phases $a$ and $\beta$ 


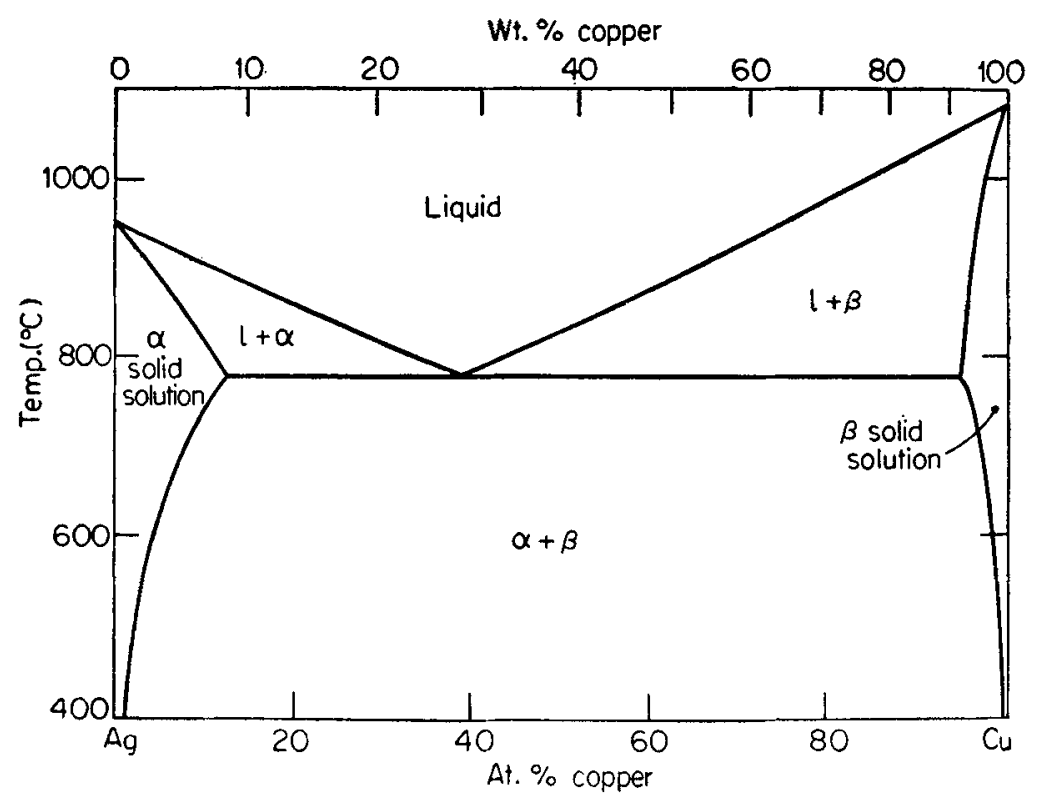

Figure 1. Equilibrium phase diagram of silver-copper.

at $780^{\circ} \mathrm{C}$. One notices that the phases invalved are solid solutions and not pure components or compounds. The relative proportions of the phases are given by mass balance equations (the Lever rule).

As shown in figure 2 the two solid phases are arranged as alternate lamellae. It is a monovariant eutactic alloy in the $\mathrm{Fe}-\mathrm{Ni} \rightarrow \mathrm{Al}$ system containing alternate lamellae of a nickel rich $(\gamma)$ phase and an iron rich $(\beta)$ phase. Alternatively the second phase can be in the form af fibres embedded in matrix phase. Figure 3 shows a eutectic alloys of $\mathrm{Al}-\mathrm{Ni}$ containing $\mathrm{Al}_{3} \mathrm{Ni}$ fibres embedded in $\mathrm{Al}$ matrix Thus eutectic alloys show the following characteristics.

(i) Solidification front is planar;

(ii) Valume fraction determines the structure : Near equal lamellar; Below $30 \%$ Rod structure

(iii) Near eutectic compositions produce dendrites, cells, glabules and divorced eutectics.

In addition this indicates that when the compasition of the alloy is off eutectic, the microstructure will be different from that of the ideal eutectic.

Though eutectic allays are known since about a century, the technological patential of their unique properties were recognised only a decade ago. Some interesting properties of eutectic alloys are listed below.

(i) High strength

$$
\sigma_{E}=\sigma_{m} V_{m}+\left(1-V_{m}\right) \sigma_{f}
$$

(ii) High directionality
(a) better thermal fatigue,
(b) better fracture resistance,
(c) better polarisation, electrical and magnetic characteristics. 

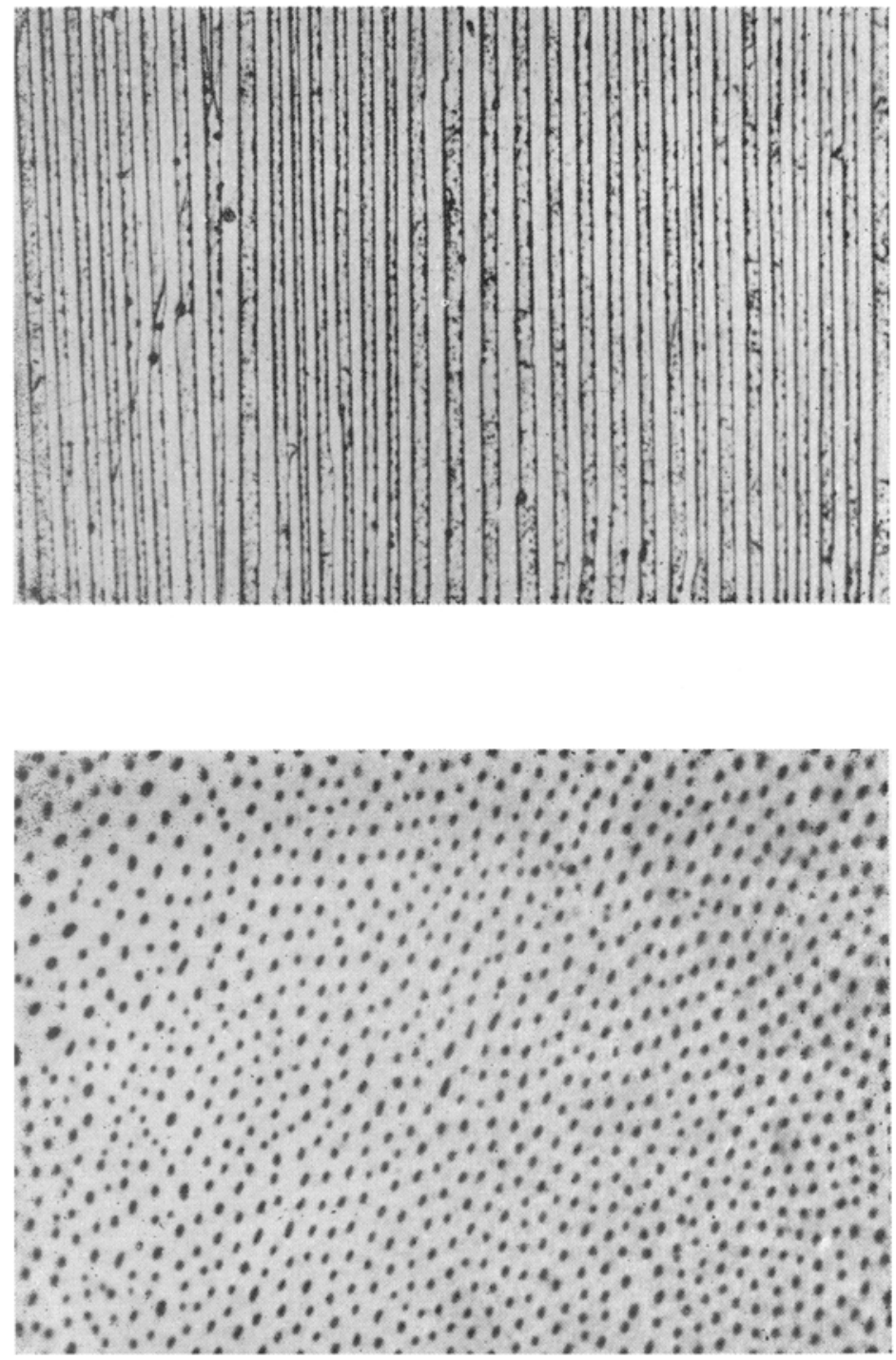

Figure 2. Longitudinal microstructure of a $\mathrm{Fe}-\mathrm{Ni}-\mathrm{Al}(\gamma-3)$ alloy.

Figure 3. Transverse microstructure of a $\mathrm{Al}-\mathrm{Ni}\left(\mathrm{Al}-\mathrm{Al}{ }_{3} \mathrm{Ni}\right)$ eutectic allay. 

(iii) Excellent compatibility and good micrastructural stability at high temperatures.

\section{Directional solidification of eutectics under gravity}

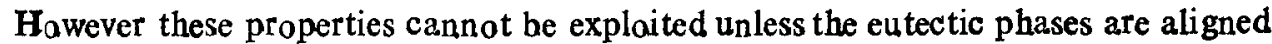
in one direction and are continuaus throughout the body. Far example, maximum strength is obtained when the phases are perfectly aligned and when the phase has an aspect ratio $(l / d)$ greater than a critical value. Such a struoture can be abtained by directionally solidifying the alloy. Directional solidification is abtained under conditions described belaw.

\subsection{Directional solidification of eutectics}

The following are the conditions necessary:

(i) Heat flux should be undirectional.

(ii) Heat extracted at the solid/liquid interface should be equal to the heat given by liquid plus the heat generated at interface

$$
K_{\mathbf{s}}(\partial T / \partial x)_{\bullet}=K_{L}\left(\frac{\partial T}{\partial x}\right)_{L}+R \frac{\Delta H}{V},
$$

where $K_{8}$ and $K_{L}$ are thermal conductivities of solid and liquid, $\Delta H$, and $V$ are enthalpy of fusion and atomic volume of the alloy and $R$ the growth speed.

(iii) Condition for plane front salidification

$$
G / R \geqslant-m \frac{C-C e}{D}=\Delta T / D,
$$

where $G$ is the tomperature gradient; $m$ the slope of liquidus ; $C-C e$ the deviation of compasition from eutectic; $\Delta T$ the freezing range and $D$ the coefficient of diffusion in liquid.

From the last equation it is clear that for truly eutectic allays the $G / R$ ratio required is zero, as $\Delta T=0$. However, alloys always contain some impurities and therefore $G / R$ is never zero for commercial alloys. It is also clear from the same equation that a ternary or higher component alloys, on eutectic traughs where liquid ultimately goes to two phase solid region with $\Delta T \neq 0$, can also be directionally solidified with plane front solidification to obtain composite structures. The $G / R$ ratio required for some recently developed eutectic alloys are shown in table 1.

A directional solidification set-up has to satisfy a number of requirements so as to produce a satisfactory structure. These requirements are summarised below.

\subsection{Requirements of experimental set-up}

(i) High $G$ because of high $R$ requirement

(ii) Absence of metal-mauld reaction

(iii) Flat isotherm for melting point of the alloy 
Table 1. $G / R$ ratios required for some eutectic alloys.

\begin{tabular}{lll}
\hline Matrix & Second phase & $\begin{array}{c}(G / R)_{\text {crttcal }} \\
\left(\mathrm{K} \mathrm{s} \mathrm{cm}^{-2}, \times 10^{4}\right)\end{array}$ \\
\hline $\mathrm{Co}, \mathrm{Cr}, \mathrm{Ni}$ & $\mathrm{TaC}$ & 25 \\
$\mathrm{Ca} \mathrm{Cr}$ & $(\mathrm{Cr}, \mathrm{Co})_{7} \mathrm{C}_{3}$ & 2.5 \\
$\mathrm{Ni}_{3} \mathrm{Al}$ & $\mathrm{Ni}_{8} \mathrm{Nb}$ & 8.3 \\
$\mathrm{Ni}_{\mathrm{Ni}} \mathrm{Al}$ & $\mathrm{Ni}_{3} \mathrm{Nb}$ & 1.8 \\
\hline
\end{tabular}

(iv) Stable and vibration free set-up

(v) Positive temperature gradient in the liquid

(vi) Protective atmosphere.

An experimental set-up meeting these requirements was fabricated at DMRL and is sketched in figtre 4. In this apparatus, an alloy bar contained in a recrystallised alumina tube, surrounded by a graphite susceptor enclosed in a quartz tube, is heated using a RF generator. The alloy and susceptor are protected by passing high purity argon. Once the molten metal temperature, judged by optical pyrometer stabilises, the alumina tube is lowered through a closaly fitting water cocled copper toroid. In this set-up temperature gradients of about $150^{\circ} \mathrm{C} / \mathrm{cm}$ have been obtained.

A monavariant eutectic alloy $\mathrm{Ni}-\mathrm{Mo}-\mathrm{Al}$ which was directionally solidified at $1.17 \mathrm{~cm} / \mathrm{hr}$ in the above set-up has a perfect microstructure as shown in figure 5. This consists of continuous fibres of molybdenum embedded in nickelbase superalloy matrix. Production of such a perfect microstructure was possible, because of a nearly planar interface as shown in figure 6 . The interface was revealed by abruptly stopping the withdrawal of the alloy from the furnace.

\subsection{Defects in eutectic structures}

Usually eutectio alloys contain various defects arising from different reasons such as subcritical $\mathbf{G} / \mathbf{R}$ thermal fluctuations, jerks/vibration and convective currents. Examples of such defects are (i) cells, (ii) dendrites, (iii) growth bands, (iv) branching and (v) ROD termination.

When $G / R$ is subcritical a cellular structure is produced as shown in figure 7. Here the planar solidification breaks down leading to curved fibres at the cell walls as shown in this figure. Figure 8 shows a more serious defect called dendrite in one of the phases of Ni-base superalloy.

Figure 9 shows a band produced by sudden change in withdrawal speed. Defects like fibre branching and rod termination cannot be easily observed. Thaugh these are not as serious as other defects, which afiect mechanical properties even in the as-grown condition, they reduce the strength when the material is exposed to high temperatures for long periods.

Figure 10 shows fibre branching and rod termination in a $\mathrm{Ni}-\mathrm{Al}-\mathrm{Cr}$ alloy. Such defects are praduced due to changes in withdrawal speed and provide a means of changing inter-fibre spacing. 


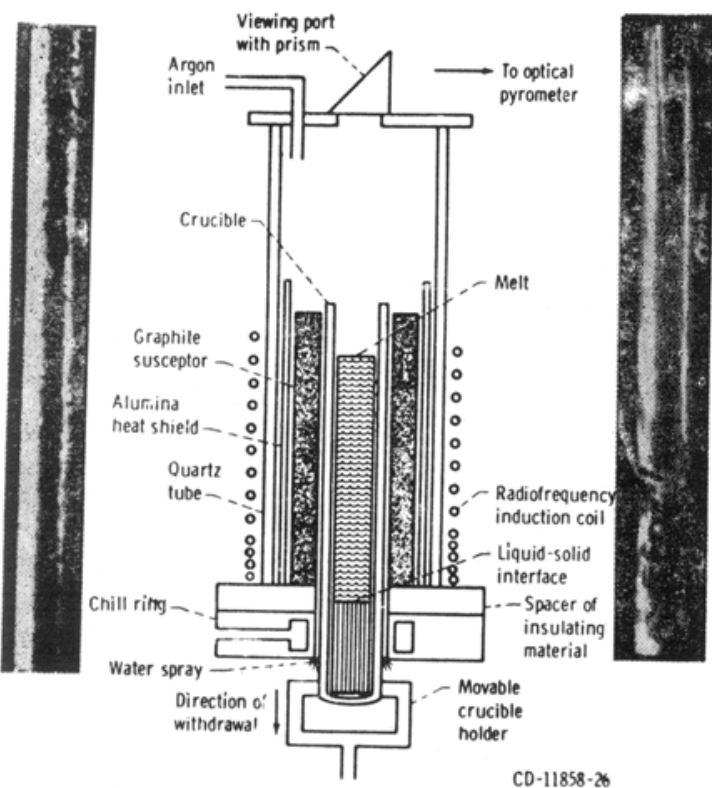

Bridgman directional solidification apparatus.

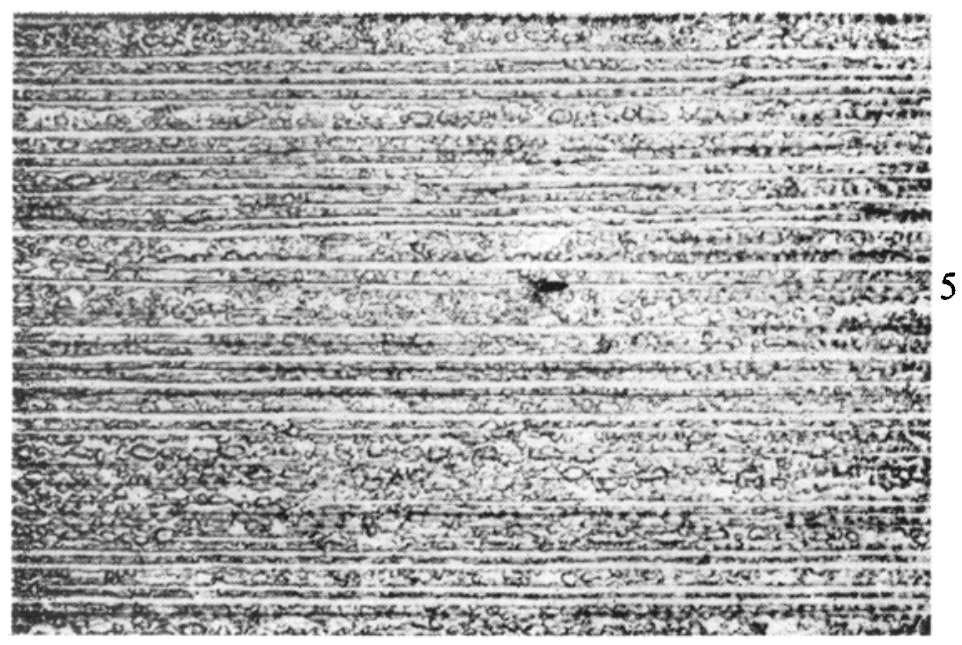

Figure 4. Experimental set-up for directional solidification of high temperature alloys.

Figure 5. Longitudinal microstructure of a $\mathrm{Ni}-\mathrm{MO}-\mathrm{Al}\left(\gamma / \gamma^{\prime}-\mathrm{Mo}\right)$ alloy. 

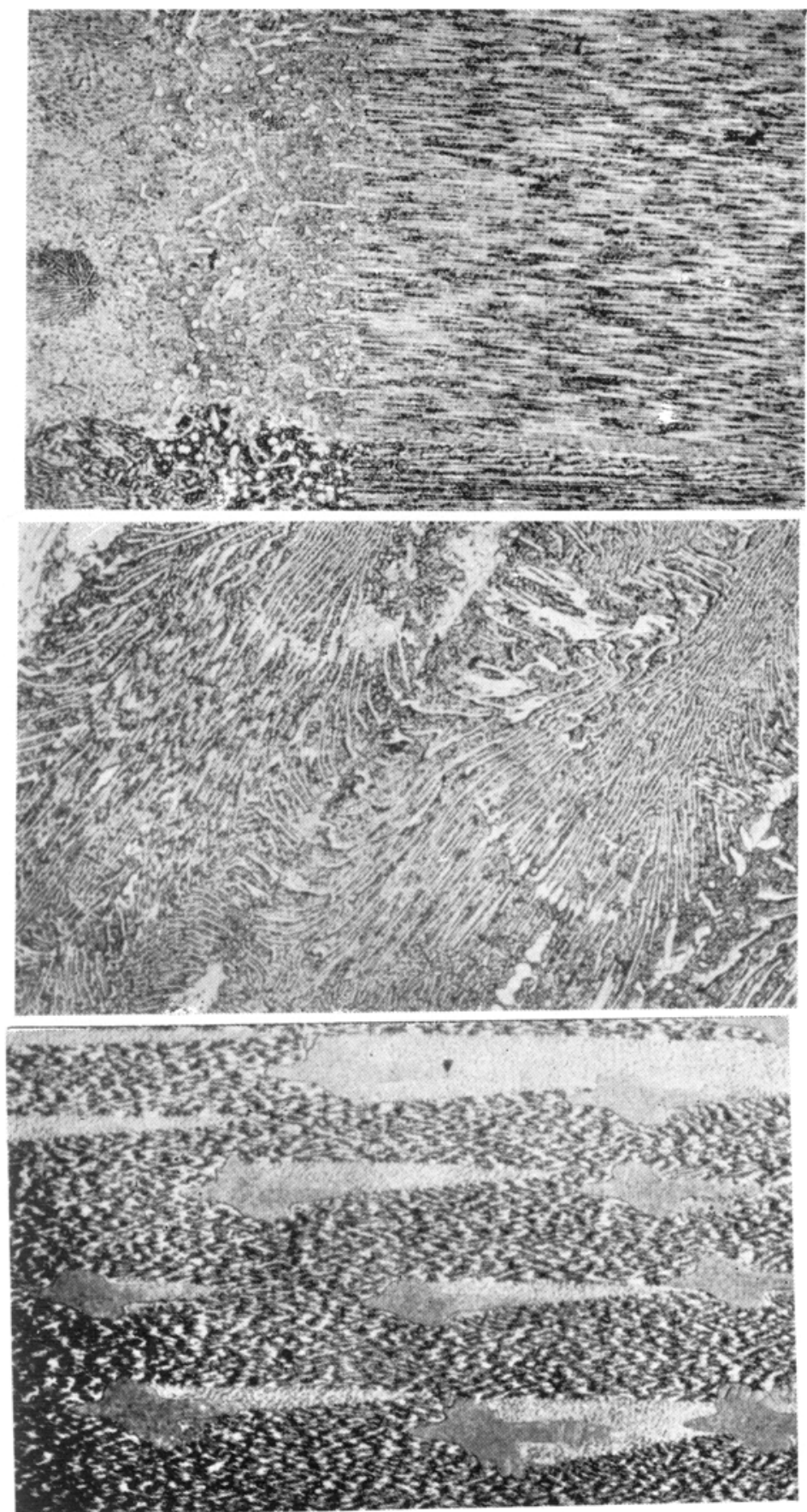

Figure 6. Solid/liquid interface in a Ni-Mo-Al $\left(\gamma / \gamma^{\prime}-\mathrm{Mo}\right)$ alloy. Figure 7. Cellular microstructure in $\gamma / \gamma^{\prime}$-Mo alloy. Figure 8. Dendritic microstructure in a $\gamma / \gamma^{\prime}$-Mo alloy. 

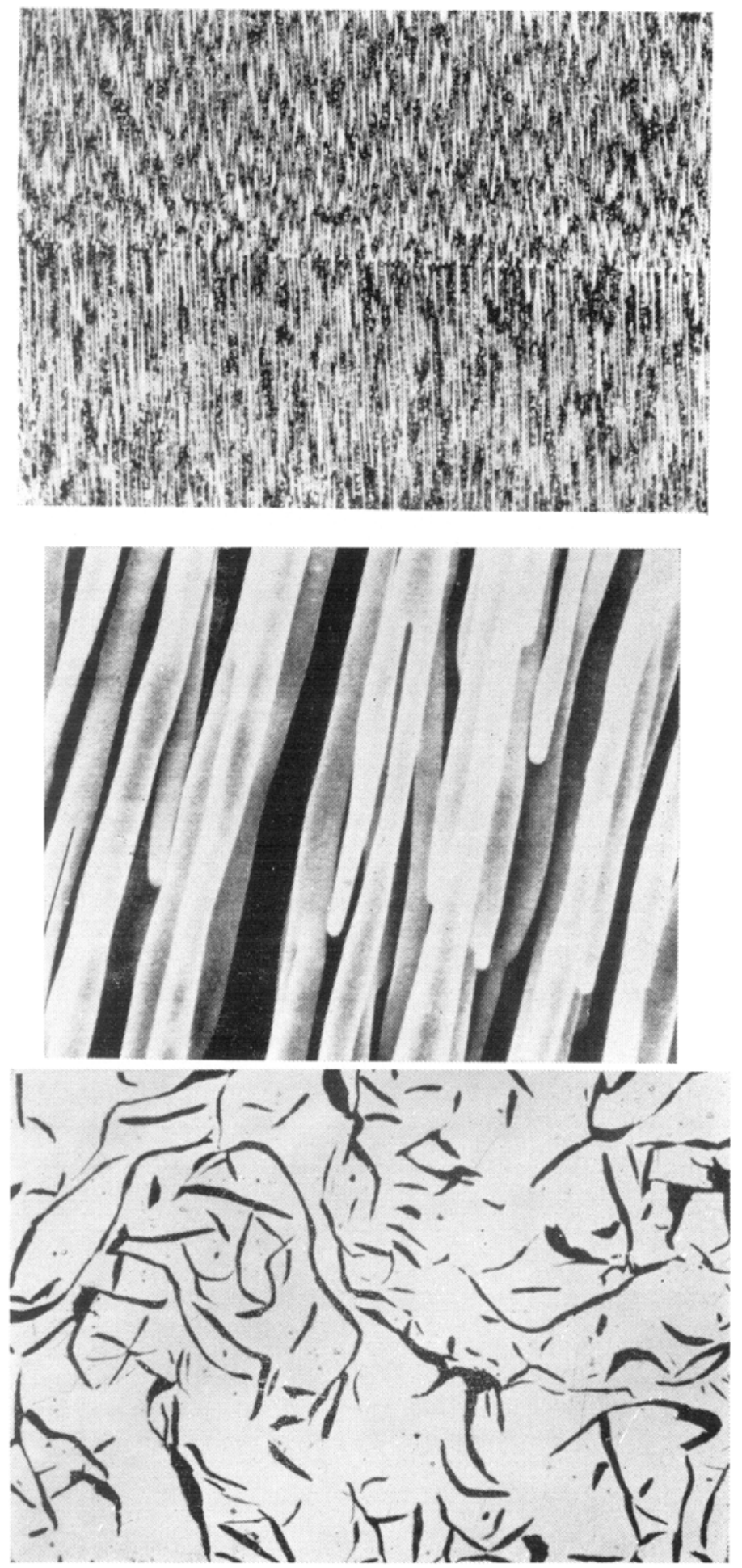

Figure 9. Banded microstructure in a $\gamma / \gamma^{\prime}$-Mo alloy; Figure 10. Fibre branchings and rod terminations in Ni-Al-Cralloy; Figure 12. Typical morphology of graphite in a grey cast iron. 



\section{Processing under microgravity conditions}

Even under ideal conditions it is not possible to produce completely perfect eutectic structures due to unavoidable convection. Though a positive temperature gradient in liquid ahead of solidification interface greatly reduces convection, it cannot completely eliminate it. It is observed that the segregation profiles obtained in directional solidification of $\gamma / \gamma^{\prime}-\mathrm{TaC}$ alloy obey Pfann's equation which assumes complete mixing in the liquid. A condition for stability against convection, taking temperature and composition effects into consideration, is

$$
\begin{aligned}
& \partial \rho / \partial x \leqslant 0 \\
& {[\partial \rho / \partial x(c)]+[\partial \rho / \partial x(T)] \leqslant 0} \\
& {[-\partial \rho / \partial x(c)] \geqslant[\partial \rho / \partial x(T)] .}
\end{aligned}
$$

The critical velacity is given by

$$
V_{e}=\frac{2 \pi^{2} g\left(\rho_{a}-\rho_{m}\right)}{9 M_{m}}
$$

where $V_{o}$ is critical velacity; $g$ is accelaration due to gravity; $\rho_{d}=$ density of region considered; $\rho_{m}=$ density of surroundings; and $M_{m}=$ viscosity of surroundings.

Convective currents are produced wherever this condition is not met in the liquid. The intensity of convective current is qualitatively given by the critical velocity. This equation suggests that the bulk movement in the liquid can be avoided by two methods; firstly by eliminating the density gradients completely and, secondly, by reducing gravitational force $g$ to very low values. The other variable, viscosity, cannot be considered as a true variable for a given alloy system.

It is expensive to eliminate density gradients in the directional solidification of complex components as the processing has to be designed separately for every component, whereas, the reduction of the gravitational force will reduce convection currents in all components with equal effectiveness. Thus, processing under microgravity conditions is an attractive proposition.

It is, however, costly to transport melting furnaces and moulds to space. Further, a large amount of power is not available in space. To overcome these handicaps a new technology has been developed recently known as "skin technology processing of components". This method consists of the following steps:

(i) The alloy piece is shaped either by conventional casting or by machining;

(ii) The shaped component is coated with a thin layer or refractory which is compatible with the alloy and which has sufficient strength at these temperatures ;

(iii) The skin coated alloy component is melted and directionally solidified.

(iv) The processed alloy component is transported back to earth and coating removed before use. If coating is beneficial in service, then the component can be used with the coating itself. These processing steps are shown in figure 11. 


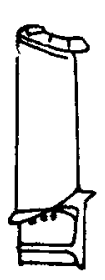

1

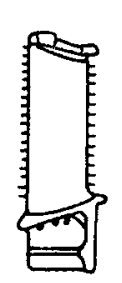

2

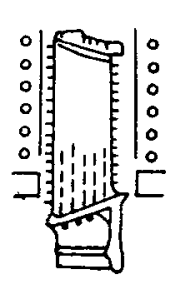

3

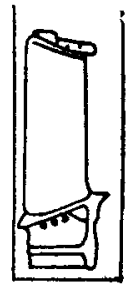

4

Figure 11. Processing steps in skin technology.

In the beginning it was considered that the large difference in thermal expansion coefficients between the alloy and its refractory coating could be a major problem as the skin material (coating) is inherently brittle. However, initial ground based experiments on ceramic-coated IN 100 showed that the ceramic coating deformed rather than cracked, under the force of differential expansion and metallostatic pressure. The coating was $\mathrm{Al}_{2} \mathrm{O}_{3}$ formed by processing like plasma spray, detonation gun plating or chemical vapour deposition to thicknesses in the range of 100 to $200 \mu$. It is possible to use thicknesses in the range of few microns in microgravity conditions. This also facilitates production of higher temperature gradients than is possible on earth, and consequently, faster solidification associated with finer microstructures. The finer microstructure exhibit better mechanical properties.

Experiments using skin technology were done successfully during six minutes free fall of the Texus (Sprenger et al 1979) rocket flights. In the Texus-I flight experiment, an IN 100 specimen was coated with a skin of $\mathrm{Al}_{2} \mathrm{O}_{3}$ and was directionally solidified. Some deformation of the skin was observed which was attributed to differential thermal expansion during melting and directional solidification. It was thought that this deformation would be avoided by proper design modification. The Texus-II flight experiment in which the design modifications were effected failed since the furnace did not work. However, some useful data were collected.

The Texus experiments were limited to the conventional alloy IN 100 as the free fall time was only 6 minutes. Much longer periods of microgravity can be abtained in the Spacelab. Sa directional solidification of eutectic allay $\gamma / \gamma^{\prime}-\mathrm{Mo}$. have been planned with solidification speeds of $0.1,0.4,0.7$ and $1 \mathrm{~mm} / \mathrm{min}$. These experiments are aimed at proving the superiority of processing of eutectics under microgravity conditions and will also demanstrate the stability of skin in contact with liquid metal for longer periads.

Though at first sight solidification of eutectic alloys under microgravity looks attractive, several diffizulties can arise in actual practice. The most impartant one is the diffisulty in determining the accurate compasition of eutectic alloys. The camposition of mast of the eutectics is known only to an accuracy of about $5000 \mathrm{ppm}$. Even the smallest composition deviations lead to breakdown of plane front solidifioation. This problem is especially severe in microgravity due to the absence of convection in liquid which can reduce solute concentration ahead of solid-liquid interface. Thus space prooessing of eutectic alloys demands an 
accurate knowledge of composition. Another difficulty that stands in the way of space pracessing technology development for eutectics is non-availability of quantitative methods of sufficient accuracy to distinglish between the levels of micrastructural perfection of space pracessed and earth-grown alloys. Therefore methods for quantitative studies of alloy structure should be improved. These points were stressed by Malmejac (1976), who also listed the following indispensable precautions to be taken for a successful experiment in microgravity.

(i) The viscosity of the eutectic liquid studied has to be as high as possible.

(ii) Systems studied must have vapour pressures as low as passible.

(iii) The walls of the containers must be wetted by every element of the alloy to avoid segregation.

(iv) The containers must be filled as completely as possible by the liquid eutectic alloy to avoid parasitic oscillations.

(v) All mechanisms, except gravity, giving convection movements must be suppresced.

In addition to the developmental work, several experiments which were impossible on earth, were conducted in space. One such interesting case is study of sulphur segregation in liquid cast iron (Luyendijk and Nieswaag 1979). In the Bridgman technique of directional sclidification on earth the rejected sulphur from solid cast iron builds u.p in the liquid at the interface. This leads to precipitation of a sulphur rich liquid phase of lower density leading to severe convoction. Therefore the true sulphur segregation profiles cannat be studied an earth. Experiments have been planned for Spacelab to study the segregation of sulphur in the absence of convection and to study the effect of sulphur on the morphalogy of graphite.

Figure 12 shows the typical morphology of graphite in a cast iron. It is expected that the absence of convection will affect the morphology of graphite.

\section{Conclusions}

(i) Absence of convection in directional solidification is likely to produce defectfree eutectic structures.

(ii) Newly developed skin technology can be applied to produce directionally solidified components. This gives additional benefit of higher temperature gradient.

(iii) Microgravity conditions can help to conduct experiments which are impossible on earth.

\section{References}

Luyendijk T and Nieswaag H 1979 Material Science in Space, Proc. Third European Symp. Grenoble, ESA Sp. 142115

Malmejac Y 1976 ESA Special Publication No. 114 p. 313

Sprenger H, Erben E, Zeilinger H and Schweitzer K 1979 Material science in space Proc. Third European Symp. Grenoble, April 1979, ESA Sp. 142101 